\section{Obituary of Dr Russell Barton}

There are a number of inaccuracies in $\mathrm{Dr}$ Henry Rollin's obituary for the late Dr Russell Barton.

Most importantly, he did not relinquish his post at Severalls because of an impolitic letter to the Lancet. Dr Barton was clearly displeased with the suggestion that he stay on as Consultant after the position of Physician Superintendent was abolished, even though he could keep the emoluments of his previous position. He moved to the United States for an opportunity to exercise direction on a hospital-wide basis, an opportunity which no longer existed in the land of his birth.

The title of the grade he held at Shenley was Senior Hospital Medical Officer, not Senior Medical Officer. Institutional Neurosis was published in 1959, not 1976. As he came to Severalls in 1960, only his experience at Shenley was included in the book. Finally, at Severalls it was not discharges that plummeted. Discharges increased - the patient census plummeted.
I can also throw some light on the question whether Dr Barton ever changed his mind on the subject of community care for the mentally ill, having maintained periodic contact with him until his infirmity made such contacts impracticable. He never regretted his role in the deinstitutionalisation movement, although he recognised, like the rest of us, that the actual performance fell well short of what he would have wished to see happen.

Miodrag Ristich Attending Psychiatrist, Lenox Hill Hospital, NewYork City. mristich@yahoo.com

\title{
the college
}

\section{Annual elections}

\section{Council and Court of Electors}

Members are reminded of their rights in connection with the forthcoming elections for the vacancies on the Court of Electors and Council. There are four vacancies on the Court of Electors. There are vacancies for two Fellows and two Members on Council. The relevant ByeLaws and Regulations are printed below.

The nominating meeting of the Council will now be held on 28 April 2003 and the last date for receiving nominations will therefore be 27 May 2003. Nomination forms are available from Andrea Woolf.

\section{Extracts from the Bye-Laws and Regulations \\ Bye-Law XXI \\ The Court of Electors \\ The Court of Electors shall be composed of}

(a) The President, Dean and Registrar, each of whom shall be an ex-officio member of the Court of Electors; and

(b) Fifteen Electors who shall be chosen in the manner hereinafter prescribed from amongst the Fellows.
At the first meeting of the Council in alternate years after the name of the President for the next ensuing College year has become known, the Council shall nominate a sufficient number of candidates for appointment as Electors to ensure an election, which will be held by a postal ballot of all Members of the College in the manner prescribed by the Regulations. Additional nominations may be lodged with the Registrar between the beginning of the then current calendar year and the end of four clear weeks after the meeting of the Council above referred to. No such nominations shall be valid unless it be supported in writing by twelve Members of the College and accompanied by the nominee's written consent to serve if elected.

\section{Regulation XIX \\ The Council}

Elections shall be held in alternate years to ensure that there are not less than six elected Members of Council and no more than six elected Fellows of the Council subject to the overall condition that no elected Member or Fellow shall serve on Council for more than six years in that capacity without a break of at least one year. At its first meeting in each alternate College year after the name of the President for the next ensuing College year has become known, the Council shall nominate the necessary number of Members and Fellows of the College to ensure that there are no more than six elected Fellows and not less than six elected Members serving on Council. Any nominee who is proposed and seconded and gives his or her consent in writing to serve, shall be validly nominated. Any twelve Members of the College may make nominations in writing at any time between the first day of January in each alternate year and the date which is four clear weeks after the meeting of the Council at which nominations were made.

Nominations other than those made by the Council shall be lodged with the Registrar and accompanied by the written consent of the candidate to serve if elected. Should there be more nominations than vacancies, an election shall be held by ballot of the Members of the College. The ballot paper shall not indicate the method of nomination or the names of those nominating. If the number of nominees does not exceed the number of vacancies, these nominees shall be declared elected at the first meeting, whether of the Council or of the Executive and Finance Committee, after the expiry of the period of four clear weeks in this paragraph referred to.

\section{obituaries}

\section{Ian Hunter Lockhart Gillies}

Formerly Consultant Psychiatrist, Stobhill General Hospital, Glasgow

Hunter Gillies, as he was always known, died on 11 September 2002. He was born in Glasgow on 4 January 1911 and attended Allan Glen's School. He studied medicine at Glasgow University, graduating $\mathrm{MB}$ ChB with Commendation in 1934. He proceeded MD with High Commendation in 1938, having obtained the DPM in 1936. He became a member of the Royal College of Physicians of
Edinburgh in 1947 and was elected as a fellow of that College in 1953. He was a founder fellow of the Royal College of Psychiatrists.

He served in the Royal Naval Volunteer Reserve from 1941 to 1946 and he was a specialist in neuropsychiatry at the Naval Hospitals in Chatham and Sydney, Australia.

He was Deputy-Physician Superintendent at the Crichton Royal Hospital, Dumfries from 1946 until 1953. His colleagues at the Crichton included Professors Willi Mayer-Gross and Martin Roth.
In 1953, Hunter Gillies returned to Glasgow on his appointment as consultant-in-charge of the psychiatric unit at Stobhill General Hospital in Glasgow. The hospital was established by the city of Glasgow early in the 20th Century and had mental observation wards from which the large psychiatric unit developed. It became an active unit, dealing with patients with a wide range of psychiatric conditions under the leadership of Hunter Gillies. He was held in high regard by colleagues in other specialities in the hospital and this helped to make the 
psychiatric unit an accepted part of the general hospital.

He leaned to the apprentice model of psychiatric training and he was an exemplary trainer. Once a trainee had worked for him, he became the gold standard. His former trainees recall their experiences of him with pleasure and gratitude and remember him personally with affection. He was of distinguished appearance and had considerable energy. Those who worked with him knew that the dryness of manner which he sometimes displayed readily gave way to warmth. He had a sharp sense of humour, and generosity and concern for others underpinned his actions.

In addition to his responsibilities at Stobhill General Hospital, at the request of the procurator-fiscal, over many years he examined persons accused of serious offences. His published work in this area highlighted the importance of alcohol as a major factor in serious offences. His forensic reports, as well as his clinical notes and letters, contained vivid thumbnail sketches, while at the same time being characterised by lucid and felicitous expression and astute judgment. He was one of the most respected Scottish psychiatrists of his generation. He retired in 1976.

He was a private man. In his younge days, he enjoyed sailing - especially off the west coast of Scotland. He maintained an interest in cooking into his later years.
In 1948, he married Mrs Isabelle Canay of Sydney, who died in 1983. In 1987, he married Mrs Margaret Richmond of Oxfordshire and relocated there. She survives him.

Hamilton Frame

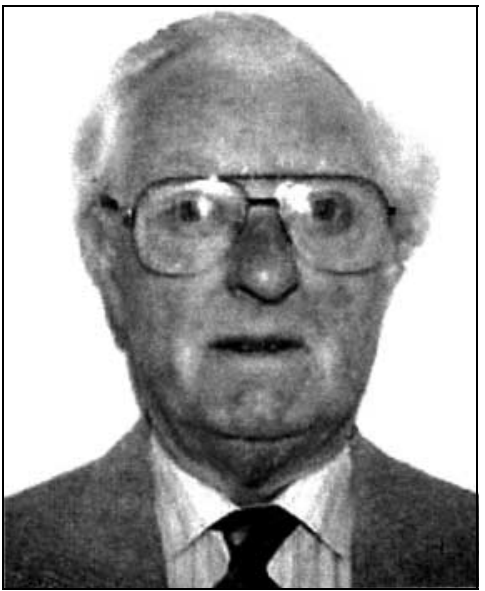

\section{Dr John Richard Theobalds}

Formerly Consultant Psychiatrist, Lancaster Health Authority

John Theobalds was born on 26 July 1923 and died from lung cancer on 28 June 2002.
He received his medical education at Westminster Hospital and qualified from there MRCS Eng., LRCP Lond and MB, BS, Lond., in 1947. After national service, mainly at a military hospital in Egypt, he returned home and worked in general medicine hospitals at Westminster and the Royal Salop Hospital, before deciding on a career in psychiatry.

To this end he served as Registrar at Park Prenett Hospital, Basingstoke and later was appointed Consultant Psychiatrist, Lancaster Health Authority and Medical Director, Priority Services NHS Trust, Lancaster. He gained the DPM. Eng in 1960, was elected MRCPsych in 1971 and proceeded FRCPsych in 1986

John's major interest was in the treatment of alcoholism and drug abuse and he opened Harvey House, currently relocated in the community in Lancaster, and was a founder trustee and committee member of Inward House, a residential therapeutic community for the treatment of drug and solvent misusers.

John's interests were widespread. He loved sport, particularly soccer: he was a lifetime Arsenal supporter and succeeded at one time to be given a trial for Chelsea! He enjoyed reading poetry and listening to music, particularly traditional jazz.

He leaves behind him his second wife, Brenda, whom he married in 1980.

\section{Mohammed Abdul Halim}

\section{reviews}

\section{Child Psychiatry and Child Protection Litigation}

By Julia Brophy with Louise Brown, Suzanne Cohen and Polly Radcliffe. London: Gaskell. 2001. 160 pp. f20.00 (hb). ISBN: 1-901242-66-8

This book is calling for a revolution in the way public child care law is supported by child psychiatry. Children caught up in care proceedings or under secure orders, or those with severe educational difficulties have a much greater need of child and adolescent mental health services (CAMHS) and yet are not usually seen as a priority. Many CAMHS are reluctant to take on this work when the family, child or young person is presented as a piece of 'court work'. Ideally, these troubled families and young people would already be known by their local service and, if court intervention were needed, it would be part of the CAMHS work and any advised interventions could be then carried out locally. Of course, there would always be some complex cases that needed an outside expert opinion or where a second opinion was more appropriate. However, the bulk of this work, as

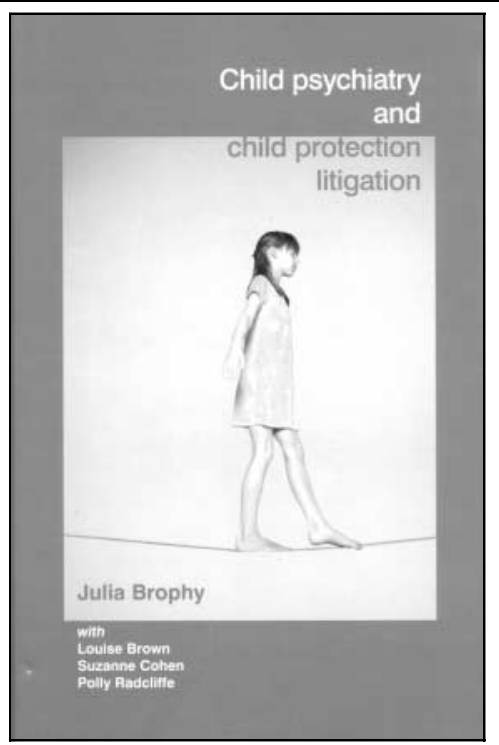

with looked after children, should be part of a local CAMHS.

Sadly, this is far from the reality, and Julia Brophy has set out to explore and document the current position. In this book, she interviews child and adolescent psychiatrists; six 'national' experts and 11 local consultants. The volume begins with a review of the Children Act 1989 and the context within which work in a public law court is undertaken. She explores how the Act has caused a considerable growth in the demand for child and adolescent mental health input into the decisionmaking process, both to determine significant harm, particularly in relation to emotional abuse, and also to assist the court in considering future options for the child, young person and family.

This is followed by a discussion of the NHS structure and the contractual arrangements that have led to the bulk of this court work being seen as category 2 work, i.e. outside the usual NHS contract. Brophy considers how this system has resulted in waiting lists and the random uptake of cases when consultants who are willing to do the work have time to do so. Is this a good way to provide vulnerable families with a service? She goes on to discuss the problems that arise when an expert opinion recommends an intervention the local service cannot or will not provide.

The implications for this public law work are considered, given the government proposal for the new consultant contract. If many experts are approaching 